\title{
Immunological Microenvironment of Hepatocellular Carcinoma and Its Clinical Implication
}

\author{
Naoshi Nishida Masatoshi Kudo \\ Department of Gastroenterology and Hepatology, Kindai University Faculty of Medicine, Osaka-Sayama, Japan
}

\section{Key Words}

Hepatocellular carcinoma - Neoantigen · Mutation .

Immune exhaustion $\cdot$ Immune checkpoint

\begin{abstract}
Despite recent advances in the treatment of hepatocellular carcinoma (HCC), the prognosis of patients with advanced stage of disease remains unfavorable. Several immune therapies have been applied to HCC, and their responses have not been satisfactory. The immune response to cancer is determined by the balance between the antigenicity of the tumor and the microenvironment of cancer tissues. Generally, accumulated genetic mutations are observed in HCC, which may lead to increased neoantigens on cancer cells with high antigenicity. However, cancer cells may evade the immune system because of alterations in molecules and cellular pathways involved in antigen processing and presentation. In addition, hypoxia in tissue induces several cytokines, chemokines, and immunosuppressive molecules from HCC cells and stromal cells. These cells also produce cytokines that attract regulatory $T$ cells infiltrating tumor tissues and contribute to establishing an immunosuppressive microenvironment. Some cancers show a good response to immune checkpoint therapy. However, prolonged stabilization of dis-
\end{abstract}

ease for this treatment is reportedly $12-41 \%$ in patients with advanced cancer. Therefore, immunosuppressive forces in the microenvironment of HCC may cause resistance to immune therapy, and modification of the tumor microenvironment may restore normal anticancer immunity. In this review, we focus on the immunological microenvironment of HCC tissues and discuss how the immunosuppressive environment of HCC should be modulated to achieve a favorable response to immune therapy, such as immune checkpoint therapy, in HCC.

(c) 2016 S. Karger AG, Basel

\section{Introduction}

Hepatocellular carcinoma (HCC) is one of the leading causes of cancer death, and the prognosis of patients with advanced tumors that are not suitable for locoregional treatment remains unfavorable [1-5]. Several types of immune therapies have been applied for the treatment for advanced cancer, including HCC, yet the response of HCC to immune therapy has not been satisfactory. However, since the degree of lymphocyte infiltration in HCC tissues is closely associated with recurrence after liver resection and transplantation $[6,7]$, the immune response

\section{KARGER}

(c) 2016 S. Karger AG, Basel

E-Mail karger@karger.com

www.karger.com/ocl
Prof. Naoshi Nishida

Department of Gastroenterology and Hepatology

Kindai University Faculty of Medicine

377-2 Ohno-Higashi, Osaka-Sayama, Osaka 589-8511 (Japan)

E-Mail naoshi@med.kindai.ac.jp 


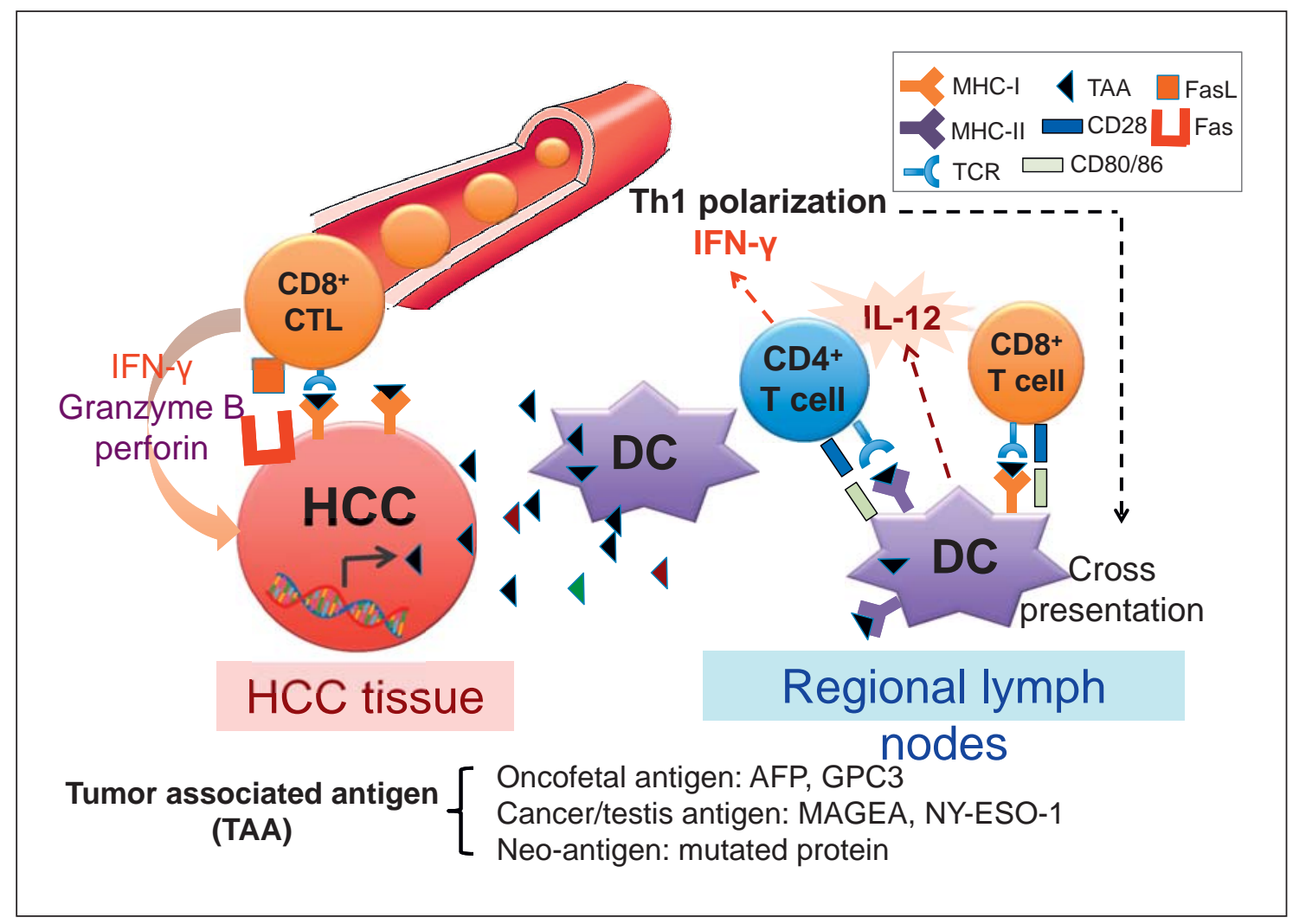

Fig. 1. Recognition and immune rejection of HCC cell by CTLs. DCs become active through the uptake and recognition of TAAs by the pattern recognition receptors. Activated DCs express costimulatory factors (CD80 and CD86) and IL-12, migrate to the regional lymph nodes, and present the processed antigen on $\mathrm{MHC}$ class II molecules for recognition by naïve CD4+ T cells. The activated CD4+ T cells differentiate to IFN- $\gamma$-producing type $1 \mathrm{Th}$ cells (Th1 polarization). Th1 cells also help DCs to present exog-

should be critical for eliminating HCC cells $[8,9]$. It was recently reported that some types of cancers, such as melanoma, non-small-cell lung cancer, and renal cell carcinoma, showed a good response to immune checkpoint therapy using antibodies against programmed cell death protein 1 (PD-1), programmed cell death 1 ligand 1 (PDL1), and cytotoxic T-lymphocyte-associated protein 4 (CTLA-4) [9-11]. However, tumor antigenicity and background immune conditions differ among individuals, affecting the response to immune therapies, including immune checkpoint blockade [8]. In this review, we focus on the immunological microenvironment of HCC tissues in the context of the disturbance of immunity in cancer and discuss how the immunosuppressive microenvironment of HCC should be modulated to achieve a favorable response in the immune therapy of HCC.

Immunotherapy in Hepatocellular Carcinoma enous antigens on MHC class I molecules to CD8+ T cells (crosspresentation), which induces the development of CD8+ CTLs. CTLs exert anticancer effects by producing IFN $-\gamma$ and releasing granzyme B and perforin. Fas-dependent mechanisms also contribute to the cytotoxic effect of T cells. AFP = Alpha-fetoprotein; MAGEA = melanoma-associated antigen; NY-ESO-1 = New York esophageal squamous cell carcinoma-1.

\section{Immune Response and Rejection of Cancer Cells}

Antigen uptake by dendritic cells (DCs) triggers the immune response and rejection of cancer cells. DCs become active through the recognition of specific molecular structures, such as pathogen-associated molecular patterns (PAMPs) in pathogens and damage-associated molecular patterns (DAMPs) in damaged cells, by the pattern recognition receptors. Activated DCs express costimulatory factors (CD80 and CD86), and inflammatory cytokines (such as interleukin-12, IL-12) migrate to the regional lymph nodes and present the processed antigen on major histocompatibility complex (MHC) class II molecules for recognition by naïve CD4+ T cells (fig. 1). Subsequently, the activation and proliferation of CD4+ T cells are triggered by binding of the antigen on MHC class

Oncology 2017;92(suppl 1):40-49 
II to $\mathrm{T}$ cell receptor (TCR) and CD80/CD86 to CD28 on the lymphocyte. The activated CD4+ T cells express the CD40 ligand that binds to CD40 on antigen-presenting cells (APCs), leading to the production of IL-12 from APCs, and enhances the differentiation of CD4+ T cells to interferon gamma (IFN- $\gamma$ )-producing type $1 \mathrm{~T}$ helper (Th1) cells (Th1 polarization). Accordingly, Th1 cells help DCs to present exogenous antigens on MHC class I molecules to CD8+ T cells (cross-presentation), which induces the development of CD8+ cytotoxic T lymphocytes (CTLs). CTLs exert anticancer effects by producing IFN- $\gamma$ and releasing granzyme B and perforin (fig. 1). They also have cytotoxic effects in cancer cells by interacting with TNF receptor superfamily member 6 (Fas) and TNF ligand superfamily member 10 on cancer cells. These processes may act in concert; sufficient induction of the Th1 response and proliferation of anticancer CTLs may be critical for the immune reaction to cancer.

\section{Cells and Cytokines Related to Immune Response and Suppression in HCC}

\section{Helper T Cells and Related Cytokines}

As described above, naïve CD4+ T cells are activated through the recognition of antigens on MHC class II molecules and co-stimulatory factors on DCs; the differentiation of CD4+ T cells depends on the profile of cytokines from APCs and CD4+ T cells. In the presence of IL-12 and IFN- $\gamma$, CD $4+$ T cells express Th1-specific T-box 1 transcription factor and differentiate into Th1 cells, leading to the activation of CD8 + T cells (or CTLs) and macrophages. In the presence of IL-4, CD4+ T cells express the transcription factor GATA binding protein 3 , which induces the differentiation of CD4+ T cells to Th2 cells. Th2 cells produce Th2 cytokines, such as IL-4, IL-5, and IL-13, and enhance the humoral immune response. It has been reported that increased expression of Th1 cytokines in HCC tissues is associated with longer patient survival, whereas expression of Th2 cytokines is associated with vascular invasion and the metastatic recurrence of cancer [12].

The presence of transforming growth factor beta (TGF- $\beta$ ) and IL-2 induces the expression of the master transcription factor forkhead box P3 (FOXP3), which induces the differentiation of naïve $\mathrm{CD} 4+\mathrm{T}$ cells to regulatory $\mathrm{T}$ cells (Tregs). These cells may play an important role in the immunosuppressive environment of cancer cells [13]. Naïve CD4+ T cells also differentiate into Th17 cells in the presence of IL- 6 and TGF- $\beta$. Th17 cells play a role in the activation of neutrophils and the progression of inflammation.

The recognition of antigen and CD80/86 induces activation of the PI3K-Akt-mTOR pathway in CD8+ T cells through signaling from TCR and CD28. One of the downstream targets of mTOR, interferon regulatory factor 4 , induces Th1-specific T-box 1 transcription factor as well as hypoxia-inducible factor 1-alpha (HIF-1a). The latter induces glucose transporter 1 on the $\mathrm{T}$ cell membrane, enhances glycolysis, and plays a role in its effector function. It is also known that immune checkpoint molecules, such as CTLA-4 and PD-1, suppress activation of the PI3K-Akt-mTOR pathway in T cells $[14,15]$.

Adenosine triphosphate (ATP) is also considered critical for the effector function of T cells. Extracellular ATP stimulates the production of IL- 2 in CD8+ T cells by increasing the intracellular concentration of calcium [16]. In contrast, adenosine binds to the adenosine A2A receptor on T cells and decreases intracellular calcium concentration. This process suppresses the proliferation and cytotoxic effects of CD8+ cells and reduces Th1 cytokines (fig. 2) [16].

\section{Regulatory T Cells}

Tregs play a central role in peripheral immune tolerance that acts as a regulator of self-reactive $\mathrm{T}$ cells. Tregs constitutively express CTLA- 4 and glucocorticoid-induced TNF receptor; their expression is regulated by FOXP3 [13]. In contrast to the stimulatory receptor CD28 on T cells, CTLA-4 acts as a repressive receptor to CD80/ CD86 and inhibits $\mathrm{T}$ cell activation. Tregs also possess IL-2 receptor subunit a (CD25) and reduce IL-2 in the microenvironment by associating with CD25. As IL-2 is essential for the differentiation and proliferation of CTLs, a decrease in IL-2 is expected to induce immune suppression (fig. 2). In addition, Tregs convert extracellular ATP into adenosine through the function of $\mathrm{CD} 38$ and $\mathrm{CD} 78$; adenosine binds to the adenosine $\mathrm{A} 2 \mathrm{~A}$ receptor on effector $\mathrm{T}$ cells and suppresses its function [17]. Tregs also produce several regulatory cytokines for immune reactions [18]. For example, TGF- $\beta$ and IL-35, which are produced by Tregs, exert suppressive effects on T cell proliferation. Granzyme B from Tregs induces the apoptosis of effector T cells [19]; Tregs express an epidermal growth factor ligand, amphiregulin, which promotes the proliferation of epithelial cells and induces the extracellular matrix $[20,21]$. These effects act in concert and contribute to establishing the immunosuppressive microenvironment of HCC tissue (fig. 2). Recently, several studies have shown that cancer cells can induce chemokines that 


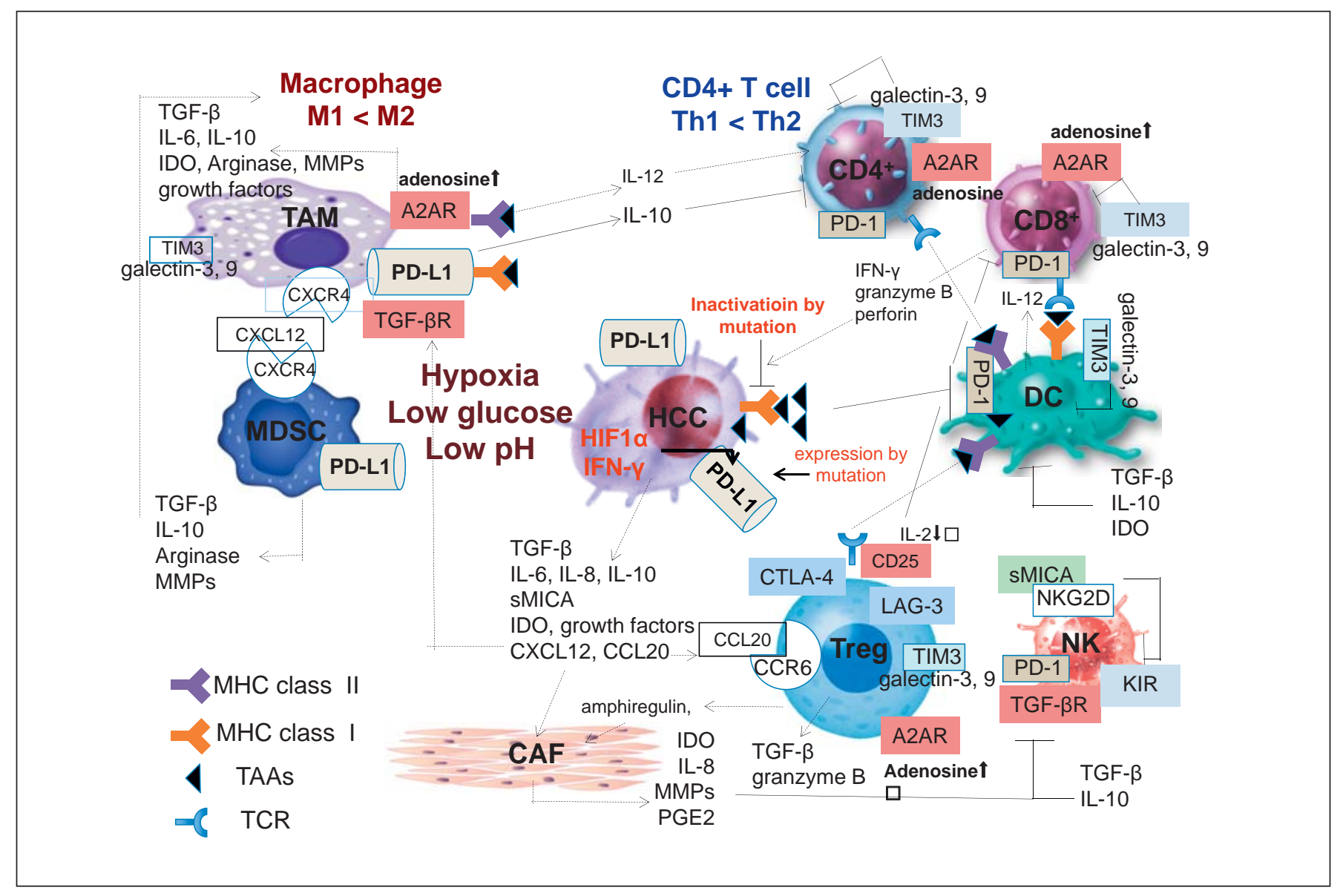

Fig. 2. Immune cells, cytokines, and molecules that contribute to the immunosuppressive microenvironment in HCC. A2AR = Human adenosine receptor A2A; CAF = cancer-associated fibroblast; CXCL12 = stromal cell-derived factor $\alpha$; LAG-3 = lymphocyte activation gene 3; MMP = matrix metalloprotease; PGE2 = prostaglandin E2.

may help Tregs to migrate into cancerous tissues [22]. Recruitment of Tregs reportedly fosters tumor progression and is associated with the poor prognosis of HCC; the chemokine $\mathrm{C}-\mathrm{C}$ motif ligand 20 cooperates with its receptor chemokine receptor 6 and induces Tregs to HCC [23].

\section{Dendritic Cells}

DCs link the innate immune systems to adaptive systems; the main function of DCs is to process antigens and present them on MHC molecules to T cells. As described above, activation of DCs takes place through the recognition of molecules with specific structures such as PAMPs and DAMPs with the pattern recognition receptors [24]. They produce cytokines responsible for the adaptive immune response, such as IL-12 and type 1 interferon, which initiate the adaptive immune response. Once activated, they induce expression of MHC class II and costimulatory factor CD80/86, migrate to the regional lymph nodes, and interact with and activate T cells (fig. 1). In addition, cross-presentation of processed antigens by DCs induces the activation of CD8+ T cells that act as CTLs. As several DAMPs can be released from cancer cells during inflammation and cell death, cross-presentation by DCs is critical for initiating an immune response to cancer (fig. 1). It has also been reported that CD14+ DCs express high levels of CTLA-4 and suppress T cell effects by inducing IL-10 and indoleamine 2,3-dioxygenase (IDO) [25]. The enzymatic action of IDO depletes tryptophan in the microenvironment, leading to the inhibition of antigen-specific $\mathrm{T}$ cell proliferation. 


\section{Macrophages}

Macrophages are found in all types of tissues and exert a phagocyte function. In addition, they play a critical role in innate and adaptive immunity by recruiting other types of immune cells and presenting antigens to T cells. Macrophages in cancerous tissues (tumor-associated macrophages, TAMs) are mainly derived from monocytes from the bone marrow and spleen. They represent different functions and features based on the tissue microenvironments. Generally, in the presence of Th1 cytokines, such as IFN- $\gamma$ and Toll-like receptor ligands, macrophages express Th1 cytokines, inflammatory cytokines (such as IL-1 $\beta$, IL-6, IL-12, and TNF- $\alpha$ ), reactive oxygen species (ROS), and nitric oxide (NO); macrophages play a critical role in pro-inflammatory response and pathogen clearance. They also induce the cytotoxicity of target cells, which is critical for anticancer immunity, and they are known as M1 macrophages. In contrast, Th2 cytokines (such as IL- 4 and IL-13) and TGF- $\beta$ induce M2 macrophages that are important for the anti-inflammatory response, wound healing, angiogenesis, and tissue remodeling. M2 macrophages produce tumor-promoting and immunosuppressive cytokines and growth factors related to tissue regeneration and angiogenesis, such as IL10 , TGF- $\beta$, arginase, prostaglandin E2, matrix metalloproteinase $7 / 9$, epidermal growth factor, insulin-like growth factor, vascular endothelial growth factor (VEGF), and platelet-derived growth factor (PDGF) [26]. Therefore, the balance between M1 and M2 in TAMs is important for cancer immune therapy (fig. 2).

Several bone marrow-derived cells resembling macrophages have also been detected in cancer tissues. These are considered precursors of granulocytes, monocytes, and macrophages and are known as myeloid-derived suppressor cells (MDSCs) [27]. These cells are recruited upon stimulation of cytokines from cancer cells and exert immunosuppressive and tumor-promoting effects. From an immunological perspective, they disturb both CD4+ and CD8+ responses through the enzymatic activity of arginase and arginine depletion [28] and induce ROS and $\mathrm{NO}$, which leads to disruption of TCR signaling (fig. 2) [29]. TGF- $\beta$ and IL-10 from MDSCs suppress natural killer (NK) cell activity and induce the expansion of Tregs, respectively [30]. The number of MDSCs is reportedly associated with the aggressiveness of HCC $[28,31]$.

The Th1/Th2 and M1/M2 balance in cancer tissues may also be affected by the interaction between MDSCs and TAMs. IL-10 derived from MDSCs downregulates IL-12 in TAMs, leading to Th2 polarization. IL-4 from Th2 induces the development of M2 macrophages (fig. 2).

\section{NK Cells}

NK cells also show a cytotoxic effect among the cells involved in the innate immune system. The role of NK cells is similar to that of CTLs in the adaptive immune system. Compared to T cells, NK cells react more quickly during immune reactions. Typically, CTLs recognize antigens on MHC and subsequently release cytokines, leading to cell lysis and apoptosis. NK cells can also recognize target cells in the absence of MHC. This ability is particularly important because cancer cells that are missing MHC I molecules can be detected and killed only by NK cells.

The mechanism of how NK cells target cancer cells missing MHC I molecules is mainly attributed to the balance in the signals from killer activation receptors (KARs) and inhibitory receptors in this cell. There are different types of KARs; one of the KARs is known as natural killer group 2D (NKG2D), which is a group of inhibitory receptors including inhibitory killer-cell immunoglobulin-like receptors (KIRs) and receptors known as immune checkpoint molecules, such as PD-1 and T-cell immunoglobulin and mucin-domain containing-3 (TIM3). For target detection, NK cells examine the target cell surface using KIRs and determine the expression level of MHC class I molecules. If engagement of KIRs to MHC class I molecules is insufficient, killing of the target cell proceeds. However, sufficient binding of MHC class I molecules to KIRs prevents killing of the target cell because the killing signal is overridden by the suppression signal.

The NKG2D ligand is known to be unregulated by DNA damage and cell stress in target cells [32]. In contrast, chronic exposure of the NKG2D ligand to NK cells can lead to downregulation of NKG2D and induce anergy of this cell [33]. Stress-induced molecules, such as MHC class I polypeptide-related sequence A and B (MICA and $\mathrm{MICB}$ ), are ligands of NKG2D and contribute to cancer elimination by NK cells. Although MICA and MICB are induced by DNA damage in many cancers [34], the soluble forms of MICs (sMICs), which are reportedly expressed in HCC, downregulate NKG2D and inhibit NK cells from killing the target (fig. 2) [35-37]. Another stress-induced ligand, the unique long 16 binding protein family, also binds to NKG2D and downregulates its expression in poorly differentiated HCCs. In addition, the recurrence of HCC in patients was significantly associated with downregulation of ULBP1 after resection [38]. A recent report showed that the soluble form of another NKG2D ligand, soluble murine UL16-binding proteinlike transcript 1, could maintain NK function by preventing NKG2D downregulation in mice [39]. Taken togeth-
44

Oncology 2017;92(suppl 1):40-49 DOI: $10.1159 / 000451015$
Nishida/Kudo 
er, inhibition of NK cell anergy in cancer immunity should be a strategy for cancer immune therapy. A recent report suggested that a subset of NK T cells with FOXP3+ had an immunosuppressive function in human HCC [40].

\section{Hepatic Stellate Cells, Endothelial Cells, and} Cancer-Associated Fibroblasts

Hepatic stellate cells and endothelial cells produce the C-X-C motif chemokine 12 (CXCL12)/stromal cell-derived factor 1. CXCL12 induces tumor growth, migration, and invasiveness through $\mathrm{C}-\mathrm{X}-\mathrm{C}$ chemokine receptor type 4 (CXCR4) on cancer cells and also recruits endothelial progenitors for tumor angiogenesis. Moreover, MDSCs, which play a crucial role in the immunosuppressive tumor environment, are recruited to tumors in a CXCL12/CXCR4-dependent manner (fig. 2) [41]. These tumor microenvironments of HCC, where the recruitment and retention of immunosuppressive cells take place [42], should disturb effective immune therapies. Endothelial cells also induce Treg induction in a TGF- $\beta$ dependent manner [43]. These cells also express FasL, which plays a role in tumor invasion into the parenchyma and elimination of infiltrating CTLs [44]. Cancer-associated fibroblasts also reportedly produce prostaglandin E2 and IDO to suppress NK function (fig. 2) [45].

\section{Antigenicity of HCC Cells and Tumor-Associated Antigens/Neoantigens}

CTLs can recognize specific antigens processed and presented on MHC class I molecules. Several types of molecules in cancer cells can act as tumor-associated antigens (TAAs), such as cancer/testis (CT) antigens and differentiation antigens.

Peptides specifically observed in the testis, ovary, and placenta may be detected in cancerous tissues, which are known as CT antigens. As germ cells do not express MHC molecules, CTLs that recognize CT antigens are typically not harmful to normal tissues and selectively attack cancer cells. Melanoma antigen and CT antigen 1 are isolated from melanoma and esophageal cancer; they are also detected in other types of cancers, including HCC [46]. TAAs such as oncofetal protein present in cancer cells are sometimes observed in corresponding normal tissues; a-fetoprotein and glypican-3 (GPC3) may also be a TAA in HCC. It has been reported that $\mathrm{T}$ cells expressing GPC3-targeted chimeric antigen receptor eliminated GPC3-positive HCC cells [47].

Immunotherapy in Hepatocellular Carcinoma
HCC generally accumulates a variety of genetic and epigenetic alterations [48-54], and the products of mutated genes may be cancer-specific neoantigens. In contrast to TAAs, neoantigens are not exposed to the immune system before the emergence of cancer cells, potentially making them ideal targets for the immune reaction. Abnormal products generated by point mutations, gene amplifications, abnormal splicing, and fusion genes may be targets of CTLs. In this case, common mutations specific for certain types of cancers may be good candidates for targeting. For example, overexpression of telomerase reverse transcriptase, which activates promoter mutation and integration of hepatitis B virus in the promoter as well as gene amplification, is common in HCC; vaccination using telomerase peptide has been reported in HCC [55]. However, as cancer cells with high antigenicity should be eliminated during clonal expansion by anticancer immune reactions, the established tumor may become resistant to immune rejection. In addition, cancers caused by few common driver mutations show fewer antigenic characteristics compared to those with many passenger mutations because of the lower levels of neoantigens. For example, cancers with mismatch-repair deficiency carry numerous passenger mutations and show a good response to immune checkpoint blockade [11]. However, cancer is heterogeneous in terms of profile of mutations, and complete elimination of cancerous tissues may be difficult.

\section{Immunological Microenvironment and Treatment of HCC}

As described above, immune cell functions are affected by the background condition of the immune system and the antigenicity of the tumor (fig. 2). During tumor development, cells with strong antigenicity should be removed by the host immune system. For example, the response of anti-TAA CD8+ T cell is higher in cases with early-stage HCC than those with advanced-stage HCC [46]; the immunosuppressive microenvironment with defects of effector T cells is more prevalent in advanced HCC tissues [56]. Chronic stimulation of TAAs can induce the expression of immune regulatory receptors and ligands and cytokines that lead to the anergy of immune cells. In HCC patients, it was reported that anti-TAA $\mathrm{CD} 8+\mathrm{T}$ cells in the peripheral blood induced IFN- $\gamma$ upon stimulation; tumors infiltrating CD8+ T cells failed to do so [46]. In addition, cancer cells may have defects in the processing and presentation of TAAs, which may be a

Oncology 2017;92(suppl 1):40-49 


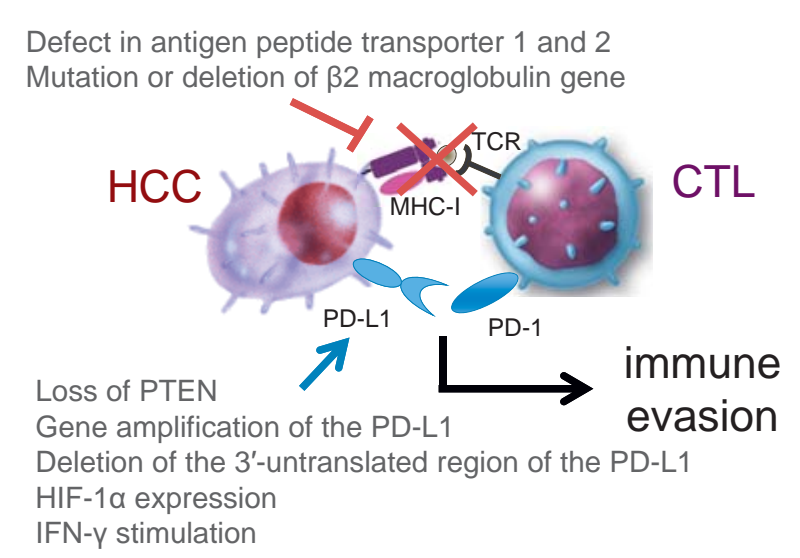

Fig. 3. T cell exhaustion in the cancer microenvironment. Mutation or deletion of antigen peptide transporter and $\beta 2$ microglobulin causes defects in MHC class I molecules. On the other hand, constitutive activation of the gene coding for PD-L1 should impair the response to cancer cells. The expression of PD-L1 is induced by the loss of phosphatase and tensin homolog deleted from chromosome 10 (PTEN) in glioma. Amplification of the PD-L1 coding gene and stabilization of PD-L1 mRNA caused by deletion of the $3^{\prime}$-untranslated region of this gene also induce increased expression of PD-L1 in leukemia, B cell lymphoma, and gastric cancer. HIF- $1 \alpha$ and stimulation by IFN- $\gamma$ also increase PD-L1 expression in the tumor.

target of the immune system [57]; mutation or deletion of $\beta 2$ microglobulin causes defects in MHC class I molecules (fig. 3) [58]. Immune checkpoint molecules, such as CTLA-4, PD-1, TIM3, lymphocyte-activating gene 3 protein, and $\mathrm{B}$ and $\mathrm{T}$ lymphocyte attenuator, are also involved in establishing an immunosuppressive environment of cancer. Constitutive activation of the gene coding for PD-L1 should impair the response to cancer cells. For example, the expression of PD-L1 is induced by the loss of phosphatase and tensin homolog deleted from chromosome 10 in glioma. Amplification of the PD-L1 coding gene and stabilization of PD-L1 mRNA caused by deletion of the $3^{\prime}$-untranslated region of this gene also induce increased expression of PD-L1 in adult T-cell leukemia, B-cell lymphoma, and gastric cancer $[59,60]$. In addition, PD-L1 is a direct target of HIF-1a. As hypoxia is a common feature of HCC tissue, HIF-1 $\alpha$ may increase PD-L1 expression in the tumor as well as MDSCs and macrophages in HCC (fig. 3) [61]. The binding of PD-1 to PDL1 on macrophages induces IL-10 release and CD4+ Tcell repression. High expression of PD-L1 and PD-1 in HCC, CD8+ T cells, and DCs is associated with tumor aggressiveness and recurrence after HCC resection [6264]. TIM 3 and its ligand, galectin-3, also suppress the Tcell response. Infiltrating CD4+ and CD8+ T cells in HCC also show increased expression of TIM3 [65].

Activation of cellular signaling pathways in cancer also induces the expression of several cytokines and growth factors; these also contribute to the establishment of the immunosuppressive environment in HCC tissues. For example, TGF- $\beta$, IL-6, IL-8, IL-10, IDO, arginase, adenosine, lactic acid, VEGF, PDGF, EGFR ligands, sIL-2, sMICA, Tregs inducing chemokines, and immune checkpoint-related molecules may be derived from HCC and stromal cells around the tumor; these molecules may act in concert and induce Treg accumulation and Th2 and M2 polarization along with HCC progression (fig. 2) [23, $28,59,60,66-73]$.

In HCC, it has been reported that Tregs suppress DC function through CTLA-4 on their surface. This prevents CD28 binding to CD80/86 and downregulates the stimulation of CD4+ and CD8+ T cells. In addition, CTLA-4 induces immunosuppressive molecules such as IL-10, arginase, and IDO. IDO is an enzyme involved in the kynurenine pathway and depletes tryptophan. Through this enzymatic effect, T-cell activation is inhibited, Treg function is enhanced, and naïve CD4+ T cells are prone to differentiate into Tregs.

IDO is expressed in HCC as well as cancer-associated fibroblasts $[45,67]$. It has also been reported that IFN- $\gamma$ from activated $\mathrm{T}$ cells upregulates IDO in macrophages and suppresses T-cell proliferation in HCC; IDO inhibitors can reverse this process [74]. The enzymatic action of arginase also depletes L-arginine and induces immune suppression. The hypoxic environment of HCC can induce arginase in TAMs and MDCS.

IFN- $\gamma$ from CD4+ and CD8+ T cells, which is critical for the induction of CTLs, induces PD-L1 on APCs and cancer cells and causes T-cell exhaustion. It also stimulates TAMs to induce galectin-9 and IL-6, which in turn induces IL-10 production from MDSCs. Galectins, such as galectin-1, -3 , and -9 , are also associated with the immune escape of HCC cells (fig. 2), and galectin-3 is associated with the poor prognosis of HCC [75]. Galectin-1 is also known as a driver of Th2 polarization and as an inducer of Tregs [76]. As described above, both galectin-3 and galectin- 9 are ligands of TIM3.

Cancer cells can release stromal cell-derived factor $1 /$ CXCL12 to induce MDSCs. MDSCs promote tumor progression and angiogenesis through VEGF production [31]. They also mediate immunosuppression by disturbing NK and T-cell functions through TGF- $\beta$, IL-10, ROS,
Nishida/Kudo 
and prostaglandin E2 production as well as the enzymatic action of IDO (fig. 2). It has been reported that HCC and Tregs produce and respond to the EGFR ligand amphiregulin, which induces HCC growth and stimulates Tregs $[21,68]$. Hypoxia can induce PD-L1 in HCC and MDSCs; the latter produces IL-10, TGF- $\beta$, and arginase. Adenosine blocks the effector function of CD4+ and $\mathrm{CD} 8+\mathrm{T}$ cells and inhibits macrophages. In addition, it also induces pro-antigenic molecules such as PDGF, VEGF, and lactic acid and contributes to HCC progression.

\section{Conclusion}

The immune response to HCC is determined by the balance between the antigenicity of the tumor and immunological microenvironment of cancer tissues. The former is also attributed to the accumulation of mutations and alterations in cellular signaling in cancer cells. Genetic and environmental factors of individuals related to immunity also affect the immune response to cancer. Immunosuppressive forces in the microenvironment of HCC may cause the resistance to immune therapy including immune checkpoint blockade, and modification of the tumor microenvironment may restore normal anticancer immunity. Therefore, comprehensive analyses of cancer tissues in terms of mutation, gene expression, cytokines/chemokines, and infiltrated cell profiles are necessary for the development of personalized immune therapy in HCC.

\section{Author Contributions}

N. Nishida drafted the manuscript and wrote the final version. $\mathrm{M}$. Kudo approved the final version of the manuscript.

\section{Disclosure Statement}

The authors have no conflict of interest to declare.

\section{References}

1 Kang TW, Rhim H: Recent advances in tumor ablation for hepatocellular carcinoma. Liver Cancer 2015;4:176-187.

2 Kudo M: Locoregional therapy for hepatocellular carcinoma. Liver Cancer 2015;4:163164 .

3 Kudo M: Surveillance, diagnosis, treatment, and outcome of liver cancer in Japan. Liver Cancer 2015;4:39-50.

4 Tsurusaki M, Murakami T: Surgical and locoregional therapy of HCC: TACE. Liver Cancer 2015;4:165-175.

5 Lencioni R, de Baere T, Martin RC, Nutting $\mathrm{CW}$, Narayanan G: Image-guided ablation of malignant liver tumors: recommendations for clinical validation of novel thermal and non-thermal technologies - a Western perspective. Liver Cancer 2015;4:208-214.

6 Wada Y, Nakashima O, Kutami R, Yamamoto O, Kojiro M: Clinicopathological study on hepatocellular carcinoma with lymphocytic infiltration. Hepatology 1998;27:407-414.

7 Unitt E, Marshall A, Gelson W, Rushbrook SM, Davies S, Vowler SL, Morris LS, Coleman N, Alexander GJ: Tumour lymphocytic infiltrate and recurrence of hepatocellular carcinoma following liver transplantation. J Hepatol 2006;45:246-253

8 Prieto J, Melero I, Sangro B: Immunological landscape and immunotherapy of hepatocellular carcinoma. Nat Rev Gastroenterol Hepatol 2015;12:681-700.
9 Kudo M: Immune checkpoint blockade in hepatocellular carcinoma. Liver Cancer 2015;4: 201-207.

10 Brahmer JR, Tykodi SS, Chow LQ, Hwu WJ, Topalian SL, Hwu P, Drake CG, Camacho LH, Kauh J, Odunsi K, Pitot HC, Hamid O, Bhatia S, Martins R, Eaton K, Chen S, Salay TM, Alaparthy S, Grosso JF, Korman AJ, Parker SM, Agrawal S, Goldberg SM, Pardoll DM, Gupta A, Wigginton JM: Safety and activity of anti-PD-L1 antibody in patients with advanced cancer. N Engl J Med 2012;366: 2455-2465.

11 Le DT, Uram JN, Wang H, Bartlett BR, Kemberling $\mathrm{H}$, Eyring $\mathrm{AD}$, Skora $\mathrm{AD}$, Luber BS, Azad NS, Laheru D, Biedrzycki B, Donehower RC, Zaheer A, Fisher GA, Crocenzi TS, Lee JJ, Duffy SM, Goldberg RM, de la Chapelle A, Koshiji M, Bhaijee F, Huebner T, Hruban RH, Wood LD, Cuka N, Pardoll DM, Papadopoulos N, Kinzler KW, Zhou S, Cornish TC, Taube JM, Anders RA, Eshleman JR, Vogelstein B, Diaz LA Jr: PD-1 blockade in tumors with mismatch-repair deficiency. N Engl J Med 2015;372:2509-2520.

12 Budhu A, Forgues M, Ye QH, Jia HL, He P, Zanetti KA, Kammula US, Chen Y, Qin LX, Tang ZY, Wang XW: Prediction of venous metastases, recurrence, and prognosis in hepatocellular carcinoma based on a unique immune response signature of the liver microenvironment. Cancer Cell 2006;10:99-111.
13 Hori S, Nomura T, Sakaguchi S: Control of regulatory $\mathrm{T}$ cell development by the transcription factor Foxp3. Science 2003;299: 1057-1061.

14 Parry RV, Chemnitz JM, Frauwirth KA, Lanfranco AR, Braunstein I, Kobayashi SV, Linsley PS, Thompson CB, Riley JL: CTLA-4 and $\mathrm{PD}-1$ receptors inhibit T-cell activation by distinct mechanisms. Mol Cell Biol 2005;25: 9543-9553.

15 Patsoukis N, Bardhan K, Chatterjee P, Sari D, Liu B, Bell LN, Karoly ED, Freeman GJ, Petkova V, Seth P, Li L, Boussiotis VA: PD-1 alters $\mathrm{T}$-cell metabolic reprogramming by inhibiting glycolysis and promoting lipolysis and fatty acid oxidation. Nat Commun 2015; 6:6692.

16 Cekic C, Linden J: Purinergic regulation of the immune system. Nat Rev Immunol 2016;16: 177-192.

17 Josefowicz SZ, Lu LF, Rudensky AY: Regulatory $\mathrm{T}$ cells: mechanisms of differentiation and function. Ann Rev Immunol 2012;30: 531-564.

18 Chen X, Du Y, Lin X, Qian Y, Zhou T, Huang $\mathrm{Z}$ : CD4+CD25+ regulatory $\mathrm{T}$ cells in tumor immunity. Int Immunopharmacol 2016;34: 244-249.

19 Vignali DA, Collison LW, Workman CJ: How regulatory $\mathrm{T}$ cells work. Nat Rev Immunol 2008;8:523-532. 
20 Berasain C, Castillo J, Perugorria MJ, Prieto J, Avila MA: Amphiregulin: a new growth factor in hepatocarcinogenesis. Cancer Lett 2007;254:30-41.

21 Zaiss DM, van Loosdregt J, Gorlani A, Bekker CP, Grone A, Sibilia M, van Bergen en Henegouwen PM, Roovers RC, Coffer PJ, Sijts AJ: Amphiregulin enhances regulatory $\mathrm{T}$ cellsuppressive function via the epidermal growth factor receptor. Immunity 2013;38: 275-284.

22 Serrels A, Lund T, Serrels B, Byron A, McPherson RC, von Kriegsheim A, Gomez-Cuadrado L, Canel M, Muir M, Ring JE, Maniati E, Sims AH, Pachter JA, Brunton VG, Gilbert N, Anderton SM, Nibbs RJ, Frame MC: Nuclear FAK controls chemokine transcription, Tregs, and evasion of anti-tumor immunity. Cell 2015;163:160-173.

23 Chen KJ, Lin SZ, Zhou L, Xie HY, Zhou WH, Taki-Eldin A, Zheng SS: Selective recruitment of regulatory $\mathrm{T}$ cell through CCR6-CCL20 in hepatocellular carcinoma fosters tumor progression and predicts poor prognosis. PLoS One 2011;6:e24671.

24 Kono H, Rock KL: How dying cells alert the immune system to danger. Nat Rev Immunol 2008;8:279-289.

25 Han Y, Chen Z, Yang Y, Jiang Z, Gu Y, Liu Y, Lin C, Pan Z, Yu Y, Jiang M, Zhou W, Cao X: Human CD14+ CTLA-4+ regulatory dendritic cells suppress $\mathrm{T}$-cell response by cytotoxic T-lymphocyte antigen-4-dependent IL-10 and indoleamine-2,3-dioxygenase production in hepatocellular carcinoma. Hepatology 2014:59:567-579.

26 Quezada SA, Peggs KS, Simpson TR, Allison JP: Shifting the equilibrium in cancer immunoediting: from tumor tolerance to eradication. Immunol Rev 2011;241:104-118.

27 Llovet JM, Bruix J: Systematic review of randomized trials for unresectable hepatocellular carcinoma: chemoembolization improves survival. Hepatology 2003;37:429-442.

28 Hoechst B, Ormandy LA, Ballmaier M, Lehner F, Kruger C, Manns MP, Greten TF, Korangy F: A new population of myeloid-derived suppressor cells in hepatocellular carcinoma patients induces CD4(+)CD25(+)Foxp3(+) T cells. Gastroenterology 2008; 135:234-243.

29 Nagaraj S, Gupta K, Pisarev V, Kinarsky L, Sherman S, Kang L, Herber DL, Schneck J, Gabrilovich DI: Altered recognition of antigen is a mechanism of CD8+ T cell tolerance in cancer. Nat Med 2007;13:828-835.

30 Li H, Han Y, Guo Q, Zhang M, Cao X: Cancer-expanded myeloid-derived suppressor cells induce anergy of NK cells through membrane-bound TGF-beta 1. J Immunol 2009; 182:240-249

31 Arihara F, Mizukoshi E, Kitahara M, Takata Y, Arai K, Yamashita T, Nakamoto Y, Kaneko S: Increase in CD14+HLA-DR -/low myeloid-derived suppressor cells in hepatocellular carcinoma patients and its impact on prognosis. Cancer Immunol Immunother 2013; 62:1421-1430.
32 Gasser S, Orsulic S, Brown EJ, Raulet DH: The DNA damage pathway regulates innate immune system ligands of the NKG2D receptor. Nature 2005;436:1186-1190.

33 Coudert JD, Scarpellino L, Gros F, Vivier E, Held W: Sustained NKG2D engagement induces cross-tolerance of multiple distinct NK cell activation pathways. Blood 2008;111: 3571-3578.

34 Champsaur M, Lanier LL: Effect of NKG2D ligand expression on host immune responses. Immunol Rev 2010;235:267-285.

35 Groh V, Wu J, Yee C, Spies T: Tumour-derived soluble MIC ligands impair expression of NKG2D and T-cell activation. Nature 2002; 419:734-738.

36 Jinushi M, Takehara T, Tatsumi T, Hiramatsu $\mathrm{N}$, Sakamori R, Yamaguchi S, Hayashi N: Impairment of natural killer cell and dendritic cell functions by the soluble form of MHC class I-related chain A in advanced human hepatocellular carcinomas. J Hepatol 2005;43: 1013-1020.

37 Kohga K, Takehara T, Tatsumi T, Ohkawa K, Miyagi T, Hiramatsu N, Kanto T, Kasugai T, Katayama K, Kato M, Hayashi N: Serum levels of soluble major histocompatibility complex (MHC) class I-related chain A in patients with chronic liver diseases and changes during transcatheter arterial embolization for hepatocellular carcinoma. Cancer Sci 2008;99: 1643-1649.

38 Kamimura H, Yamagiwa S, Tsuchiya A, Takamura M, Matsuda $\mathrm{Y}$, Ohkoshi S, Inoue $\mathrm{M}$, Wakai T, Shirai Y, Nomoto M, Aoyagi Y: Reduced NKG2D ligand expression in hepatocellular carcinoma correlates with early recurrence. J Hepatol 2012;56:381-388.

39 Deng W, Gowen BG, Zhang L, Wang L, Lau $\mathrm{S}$, Iannello A, Xu J, Rovis TL, Xiong N, Raulet DH: Antitumor immunity. A shed NKG2D ligand that promotes natural killer cell activation and tumor rejection. Science 2015;348: 136-139.

40 Li X, Peng J, Pang Y, Yu S, Yu X, Chen P, Wang W, Han W, Zhang J, Yin Y, Zhang Y: Identification of a FOXP3(+)CD3(+) CD56(+) population with immunosuppressive function in cancer tissues of human hepatocellular carcinoma. Sci Rep 2015;5:14757.

41 Chen Y, Huang Y, Reiberger T, Duyverman AM, Huang P, Samuel R, Hiddingh L, Roberge S, Koppel C, Lauwers GY, Zhu AX, Jain RK, Duda DG: Differential effects of sorafenib on liver versus tumor fibrosis mediated by stromal-derived factor 1 alpha/C-X-C receptor type 4 axis and myeloid differentiation antigen-positive myeloid cell infiltration in mice. Hepatology 2014;59:1435-1447.

42 Obermajer N, Muthuswamy R, Odunsi K, Edwards RP, Kalinski P: PGE(2)-induced CXCL12 production and CXCR4 expression controls the accumulation of human MDSCs in ovarian cancer environment. Cancer Res 2011;71:7463-7470.
43 Carambia A, Freund B, Schwinge D, Heine M, Laschtowitz A, Huber S, Wraith DC, Korn T, Schramm C, Lohse AW, Heeren J, Herkel J: TGF- $\beta$-dependent induction of $\mathrm{CD} 4^{+} \mathrm{CD} 25^{+} \mathrm{Foxp}^{+}{ }^{+}$Tregs by liver sinusoidal endothelial cells. J Hepatol 2014;61:594-599.

44 Motz GT, Santoro SP, Wang LP, Garrabrant T, Lastra RR, Hagemann IS, Lal P, Feldman MD, Benencia F, Coukos G: Tumor endothelium FasL establishes a selective immune barrier promoting tolerance in tumors. Nat Med 2014;20:607-615.

45 Li T, Yang Y, Hua X, Wang G, Liu W, Jia C, Tai Y, Zhang Q, Chen G: Hepatocellular carcinoma-associated fibroblasts trigger NK cell dysfunction via PGE2 and IDO. Cancer Lett 2012;318:154-161.

46 Flecken T, Schmidt N, Hild S, Gostick E, Drognitz O, Zeiser R, Schemmer P, Bruns H, Eiermann T, Price DA, Blum HE, NeumannHaefelin C, Thimme R: Immunodominance and functional alterations of tumor-associated antigen-specific CD8+ T-cell responses in hepatocellular carcinoma. Hepatology 2014; 59:1415-1426.

47 Gao H, Li K, Tu H, Pan X, Jiang H, Shi B, Kong J, Wang H, Yang S, Gu J, Li Z: Development of $\mathrm{T}$ cells redirected to glypican- 3 for the treatment of hepatocellular carcinoma. Clin Cancer Res 2014;20:6418-6428.

48 Nishida N, Nagasaka T, Nishimura T, Ikai I, Boland CR, Goel A: Aberrant methylation of multiple tumor suppressor genes in aging liver, chronic hepatitis, and hepatocellular carcinoma. Hepatology 2008;47:908-918.

49 Nishida N, Goel A: Genetic and epigenetic signatures in human hepatocellular carcinoma: a systematic review. Curr Genomics 2011; 12:130-137.

50 Nishida N, Kudo M, Nagasaka T, Ikai I, Goel A: Characteristic patterns of altered DNA methylation predict emergence of human hepatocellular carcinoma. Hepatology 2012;56: 994-1003.

51 Nishida N, Arizumi T, Takita M, Kitai S, Yada N, Hagiwara S, Inoue T, Minami Y, Ueshima K, Sakurai T, Kudo M: Reactive oxygen species induce epigenetic instability through the formation of 8-hydroxydeoxyguanosine in human hepatocarcinogenesis. Dig Dis 2013; 31:459-466.

52 Nishida N, Kudo M: Recent advancements in comprehensive genetic analyses for human hepatocellular carcinoma. Oncology 2013;84 (suppl 1):93-97.

53 Nishida N, Kudo M: Alteration of epigenetic profile in human hepatocellular carcinoma and its clinical implications. Liver Cancer 2014;3:417-427.

54 Nishida N, Nishimura T, Nakai T, Chishina H, Arizumi T, Takita M, Kitai S, Yada N, Hagiwara S, Inoue T, Minami Y, Ueshima K, Sakurai T, Kudo M: Genome-wide profiling of DNA methylation and tumor progression in human hepatocellular carcinoma. Dig Dis 2014;32:658-663. 
55 Greten TF, Forner A, Korangy F, N'Kontchou G, Barget N, Ayuso C, Ormandy LA, Manns MP, Beaugrand M, Bruix J: A phase II open label trial evaluating safety and efficacy of a telomerase peptide vaccination in patients with advanced hepatocellular carcinoma. BMC Cancer 2010;10:209.

56 Willimsky G, Schmidt K, Loddenkemper C, Gellermann J, Blankenstein T: Virus-induced hepatocellular carcinomas cause antigen-specific local tolerance. J Clin Invest 2013;123: 1032-1043.

57 Mittal D, Gubin MM, Schreiber RD, Smyth MJ: New insights into cancer immunoediting and its three component phases - elimination, equilibrium and escape. Curr Opin Immunol 2014;27:16-25.

58 Bernal M, Ruiz-Cabello F, Concha A, Paschen A, Garrido F: Implication of the beta2-microglobulin gene in the generation of tumor escape phenotypes. Cancer Immunol Immunother 2012;61:1359-1371.

59 Blay J, White TD, Hoskin DW: The extracellular fluid of solid carcinomas contains immunosuppressive concentrations of adenosine. Cancer Res 1997;57:2602-2605.

60 Colegio OR, Chu NQ, Szabo AL, Chu T, Rhebergen AM, Jairam V, Cyrus N, Brokowski CE, Eisenbarth SC, Phillips GM, Cline GW, Phillips AJ, Medzhitov R: Functional polarization of tumour-associated macrophages by tumour-derived lactic acid. Nature 2014;513: 559-563.

61 Noman MZ, Desantis G, Janji B, Hasmim M, Karray S, Dessen P, Bronte V, Chouaib S: PDL1 is a novel direct target of HIF-1alpha, and its blockade under hypoxia enhanced MDSCmediated T cell activation. J Exp Med 2014; 211:781-790.
62 Gao Q, Wang XY, Qiu SJ, Yamato I, Sho M, Nakajima Y, Zhou J, Li BZ, Shi YH, Xiao YS, $\mathrm{Xu}$ Y, Fan J: Overexpression of PD-L1 significantly associates with tumor aggressiveness and postoperative recurrence in human hepatocellular carcinoma. Clin Cancer Res 2009; 15:971-979.

63 Krempski J, Karyampudi L, Behrens MD, Erskine CL, Hartmann L, Dong H, Goode EL, Kalli KR, Knutson KL: Tumor-infiltrating programmed death receptor-1+ dendritic cells mediate immune suppression in ovarian cancer. J Immunol 2011;186:6905-6913.

64 Shi F, Shi M, Zeng Z, Qi RZ, Liu ZW, Zhang JY, Yang YP, Tien P, Wang FS: PD-1 and PD-L1 upregulation promotes CD8(+) T-cell apoptosis and postoperative recurrence in hepatocellular carcinoma patients. Int J Cancer 2011;128:887-896.

$65 \mathrm{Li} \mathrm{H}, \mathrm{Wu} \mathrm{K}$, Tao K, Chen L, Zheng Q, Lu X, Liu J, Shi L, Liu C, Wang G, Zou W: Tim-3/ galectin-9 signaling pathway mediates T-cell dysfunction and predicts poor prognosis in patients with hepatitis $B$ virus-associated hepatocellular carcinoma. Hepatology 2012;56: 1342-1351.

66 Yan W, Liu X, Ma H, Zhang H, Song X, Gao L, Liang X, Ma C: Tim-3 fosters HCC development by enhancing TGF- $\beta$-mediated alternative activation of macrophages. Gut 2015; 64:1593-1604.

67 Pan K, Wang H, Chen MS, Zhang HK, Weng DS, Zhou J, Huang W, Li JJ, Song HF, Xia JC: Expression and prognosis role of indoleamine 2,3-dioxygenase in hepatocellular carcinoma. J Cancer Res Clin Oncol 2008;134:1247-1253.

68 Castillo J, Goni S, Latasa MU, Perugorria MJ, Calvo A, Muntane J, Bioulac-Sage P, Balabaud C, Prieto J, Avila MA, Berasain C: Amphiregulin induces the alternative splicing of p73 into its oncogenic isoform DeltaEx2p73 in human hepatocellular tumors. Gastroenterology 2009;137:1805-1815.e1-4.
69 Gessi S, Merighi S, Sacchetto V, Simioni C, Borea PA: Adenosine receptors and cancer. Biochim Biophys Acta 2011;1808:1400-1412.

70 Hato T, Goyal L, Greten TF, Duda DG, Zhu AX: Immune checkpoint blockade in hepatocellular carcinoma: current progress and future directions. Hepatology 2014;60:17761782.

71 Yan W, Han P, Zhou Z, Tu W, Liao J, Li P, Liu M, Tian D, Fu Y: Netrin-1 induces epithelialmesenchymal transition and promotes hepatocellular carcinoma invasiveness. Dig Dis Sci 2014;59:1213-1221.

72 Zhang Z, Zhang Y, Sun XX, Ma X, Chen ZN: MicroRNA-146a inhibits cancer metastasis by downregulating VEGF through dual pathways in hepatocellular carcinoma. Mol Cancer 2015; $14: 5$.

73 Lu Y, Lin N, Chen Z, Xu R: Hypoxia-induced secretion of platelet-derived growth factorBB by hepatocellular carcinoma cells increases activated hepatic stellate cell proliferation, migration and expression of vascular endothelial growth factor-A. Mol Med Rep 2015; 11:691-697.

74 Zhao Q, Kuang DM, Wu Y, Xiao X, Li XF, Li TJ, Zheng L: Activated CD69+ T cells foster immune privilege by regulating IDO expression in tumor-associated macrophages. J Immunol 2012;188:1117-1124.

75 Cedeno-Laurent F, Dimitroff CJ: Galectins and their ligands: negative regulators of antitumor immunity. Glycoconj J 2012;29:619625 .

76 Cedeno-Laurent F, Opperman M, Barthel SR, Kuchroo VK, Dimitroff CJ: Galectin-1 triggers an immunoregulatory signature in Th cells functionally defined by IL-10 expression. J Immunol 2012;188:3127-3137. 